\title{
Spring wheat varieties resistance to biotic stressors
}

\author{
Toropova E.Yu. ${ }^{1,2 *}$, Trunov R.I. ${ }^{1}$, Piskarev V.V. ${ }^{3}$ \\ ${ }^{1}$ Novosibirsk State Agrarian University, Novosibirsk, Russia \\ ${ }^{2}$ All-Russian Research Institute of Phytopathology, Moscow region, Russia \\ ${ }^{3}$ Institute of Cytology and Genetics, Siberian Branch of the Russian Academy of Sciences, Novosibirsk, \\ Russia \\ * email: $89139148962 @ y a n d e x . r u$
}

The purpose of the research was to identify resistant to a complex of biotic stressors pathogens of soil infections (Helminthosporium sativum Sacc., Fusarium spp. Link.) and cereal flies (Oscinella pusilla Mg., Phorbia genitalis Schnalb., Mayetiola destructor Say.) spring wheat varieties from the collection of the Institute of Cytology and Genetics. The studies were carried out in 2020-2021 in the northern forest-steppe of the Ob region (West Siberia) using generally accepted methods. Among 20 varieties of spring wheat collection from different regions of Russia and countries of the world, no varieties were found that were not affected by root rot and were not damaged by pests. The zonal threshold of root rot harmfulness was exceeded to 5 times. The difference in the varieties infestation by root rot was 2.3 times at the seedlings stage, and 1.5 times at the end of the growing season. The significant differences in the root rot etiology in varieties were revealed, which was due to the specific induction by varieties of the rhizosphere soil suppressiveness to the pathogenic micromycetes species. The correlation coefficient of the soil suppressiveness induction to Fusarium poae by varieties and its representation in root rot pathogenic complexes was $R=-0.638 \pm 0.318$, the same correlation coefficient to Fusarium oxysporum was $R=-0.844 \pm 0.203(P<0.01)$. Damage to spring wheat main stems by cereal flies reached 10 thresholds and varied by varieties to 3.7 times. The correlation coefficient between the root rot incidence and stems damage by cereal flies was $R=0.713 \pm 0.092$. Under conditions of massive damage by cereal flies, the varieties could not fully manifest genetically determined immune properties, especially in the second half of the growing season.

Acknowledgements: The reported study was funded by RFBR, project number 20-01600079. 